\title{
Hidrólisis ácida de cascarilla de arroz para la generacion de azúcares reductores
}

\author{
Jorge Sigüencia, Jaime Soler, Miguel Menéndez \\ Grupo de Catálisis, Separaciones Moleculares e Ingeniería de Reactores (CREG) \\ Instituto de Investigación en Ingeniería de Aragón (I3A) \\ Universidad de Zaragoza, Mariano Esquillor s/n, 50018, Zaragoza, Spain. \\ Tel. +34-876555481, e-mail: jorge.siguencia@ucuenca.edu.ec
}

\section{Resumen}

Se ha han realizados ensayos sobre la reacción de hidrólisis de cascarilla de arroz para generar azucares reductores totales (ART). Se han modificando variables como tiempo, temperatura, concentración de ácido y concentración de biomasa. Finalmente, el mejor resultado (ID A100) generó 92,9 mg ART/g Biomasa.

\section{Introducción}

En el Ecuador la producción de arroz en cáscara corresponde aproximadamente a 1,6 millones de toneladas anuales, donde los residuos de cascarilla representan el $22 \%$ del total producido, esto es 352000 t/año de cascarilla [1]. La hidrólisis ácida de biomasa permite obtener azúcares fermentables, a partir de los que se puede obtener etanol mediante fermentación. Esto podría suponer una fuente de energía renovable a partir de un residuo agrícola.

El objetivo de este estudio experimental es obtener información sobre la generación de azúcares reductores a partir de la cascarilla de arroz, mediante hidrólisis ácida. Para ello se tomó una muestra representativa de cascarilla generada en el país, se caracterizó dicha muestra y se estudiaron los productos de hidrólisis obtenidos en distintas condiciones. Para la hidrólisis ácida, se modificaron las variables Tiempo, Temperatura, Concentración de ácido y cantidad de biomasa.

\section{Experimental}

Se han llevado a cabo ensayos de hidrólisis en un reactor discontinuo. Las variables estudiadas fueron: tiempo (30, 60 y $90 \mathrm{~min})$, temperatura $(100,120$ y $\left.150{ }^{\circ} \mathrm{C}\right)$, concentración de ácido sulfúrico $(0,1$ y 1,5 $\%$ peso) y de biomasa (1, 1,5 y $5 \%$ peso).

En cada ensayo se pesó la masa de muestra especificada, con un tamaño de partícula inferior a 0,075mm (malla ASTM-E-11 N²00). Se completó el volumen a $100 \mathrm{ml}$ con agua destilada y se obtuvo el hidrolizado en un reactor tipo batch totalmente hermético, con la combinación de variables antes descrita. Se enfrió y estabilizó el hidrolizado con $\mathrm{NaOH}$ al 30\% hasta alcanzar pH neutro (5-7) y se filtró con papel Whatman 42 .

\section{Biomasa:}

Se utilizó como biomasa la cascarilla de arroz SFL09 e INIAP 14. La tabla 1 muestra los resultados del análisis estructural.

Tabla 1: Composición de la cascarilla de arroz (SFL09/INIAP14) en base seca libre de extractos

\begin{tabular}{|l|c|}
\hline COMPONENTE & \% PESO \\
\hline Celulosa & 45 \\
\hline Hemicelulosa & 11 \\
\hline Lignina & 28 \\
\hline Cenizas & 16 \\
\hline
\end{tabular}

\section{Análisis de productos:}

La concentración de azucares reductores se determinó mediante la espectrofotometría UV, a partir de la absorbancia a $540 \mathrm{~nm}$ [2]. El equipo se calibró con glucosa y xilosa comerciales. Para cuantificar productos de degradación se emplearon las absorbancias de 277 y $285 \mathrm{~nm}$ [3].

\section{Resultados}

En los experimentos en que no se utiliza ácido se obtuvo un rendimiento a azucares reductores inferior al 2\%. Por otro lado, cuando se trabajó con concentraciones de biomasa del 5\%, la solución hidrolizable se volvía viscosa haciendo difícil su manipulación. 
La Tabla 2 muestra un resumen de los mejores resultados obtenidos en los experimentos de hidrolisis. Cuando se incorpora ácido, la temperatura y el tiempo de reacción juegan un papel importante en la generación de azúcares reductores (ART). En general, la mayor parte de la reacción se ha producido a los 60 minutos, siendo el aumento de rendimiento al pasar a 90 minutos relativamente pequeño, simpre inferior al $10 \%$ y tanto menor cuanto mayor es la temperatura. $\mathrm{Al}$ incrementar la temperatura bajo las mismas condiciones experimentales, se incrementa la generación de ART. Así, cuando se incrementa de $100^{\circ} \mathrm{C}$ hasta $120^{\circ} \mathrm{C}$ se produce un incremento de azucares reductores del $31 \%$ aproximadamente. El incremento de ácido produce mayor cantidad de ART a bajas temperaturas $\left(100^{\circ} \mathrm{C}\right)$. Sin embargo cuando cuando se utiliza la mayor concentración de ácido (1,5\%), los los ART decrecen al aumentar la temperatura. Alta temperatura $\left(150^{\circ} \mathrm{C}\right)$ y tiempo de operación largo (90 minutos) favorecen la obtención de furfural.

Al aumentar la cantidad de biomasa no se afecta significativamente a la generación de ART, a excepción de que al trabajar con un 5\% disminuyen los ART. El rendimiento a productos de degradación (furfural e hidroximetil furfural) no supera el $0,2 \%$ en ningún caso.

\section{Conclusiones}

El mayor rendimiento que se obtiene en los experimentos de hidrólisis, genera 92,9 mg de ART / g biomasa seca.

Si se emplean estos ART en la obtención de etanol anhidro mediante fermentación se generarían 19 millones de litros/año según el rendimiento descrito por Albarracín y cols. [3].

La producción de etanol de caña en Ecuador en el año 2015 fue de 53,7 millones de litros, por lo que potencialmente la cantidad de etanol que se podría generar a partir de cascarilla de arroz representaría un $35,24 \%$ de la producción actual.

Tabla 2. Experimentos hidrólisis ácida de cascarilla de arroz.

\begin{tabular}{|c|c|c|c|c|c|c|c|}
\hline ID & $\begin{array}{l}\text { Tiempo } \\
\text { min }\end{array}$ & $\begin{array}{c}\text { Temperatura } \\
{ }^{\circ} \mathrm{C}\end{array}$ & $\begin{array}{l}\text { Acido } \% \\
\text { V/V }\end{array}$ & $\begin{array}{c}\text { Biomasa } \\
\%\end{array}$ & $\begin{array}{c}\mathrm{mg} \mathrm{ART} / \mathrm{g} \\
\text { biomasa }\end{array}$ & $\begin{array}{c}\text { mg de } \\
\text { Furfural/g } \\
\text { biomasa }\end{array}$ & $\begin{array}{c}\text { mg de } \\
\mathrm{HMF} / \mathrm{g} \\
\text { biomasa }\end{array}$ \\
\hline A29 & 60 & 100 & 1 & 1 & 51,2 & 7,4 & 0,9 \\
\hline A30 & 90 & 100 & 1 & 1 & 50,0 & 8,8 & 1,4 \\
\hline A39 & 60 & 100 & 1 & 1,5 & 49,3 & 7,6 & 4,1 \\
\hline A40 & 90 & 100 & 1 & 1,5 & 49,5 & 7,9 & 3,9 \\
\hline A49 & 60 & 100 & 1 & 5 & 10,9 & 0,5 & 2,2 \\
\hline A50 & 90 & 100 & 1 & 5 & 11,9 & 0,2 & 2,7 \\
\hline A59 & 60 & 100 & 1,5 & 1 & 62,2 & 9,8 & 3,6 \\
\hline A60 & 90 & 100 & 1,5 & 1 & 66,7 & 10,1 & 5,0 \\
\hline A69 & 60 & 100 & 1,5 & 1,5 & 51,9 & 9,4 & 4,5 \\
\hline A70 & 90 & 100 & 1,5 & 1,5 & 55,3 & 9,7 & 4,7 \\
\hline A79 & 60 & 120 & 1 & 1 & 75,6 & 7,1 & 6,3 \\
\hline A80 & 90 & 120 & 1 & 1 & 80,4 & 9,0 & 6,0 \\
\hline A89 & 60 & 120 & 1,5 & 1,5 & 73,4 & 8,5 & 5,8 \\
\hline A90 & 90 & 120 & 1,5 & 1,5 & 72,7 & 11,6 & 2,2 \\
\hline A99 & 60 & 150 & 1 & 1 & 91,7 & 14,6 & 6,5 \\
\hline A100 & 90 & 150 & 1 & 1 & 92,9 & 15,3 & 6,4 \\
\hline A109 & 60 & 150 & 1,5 & 1,5 & 61,4 & 11,8 & 3,8 \\
\hline A110 & 90 & 150 & 1,5 & 1,5 & 61,5 & 17,3 & 0,4 \\
\hline
\end{tabular}

\section{REFERENCIAS}

[1] ECHEVERRÍA, M.A., and LÓPEZ, O.A., Caracterización energética de la cascarilla de arroz para su aplicación en la generación de energía termoeléctrica, Escuela Politécnica Nacional de Ecuador, 2010. Proyecto de Titulación.

[2] OTERO, M. A. y cols, Limitaciones del método del ácido 3,5 DNS en mieles finales, Revista ICIDCA No1, 1986.

[3] ALBARRACÍN， K.G. JARAMILLO K.I. and ALBUJA M.. Obtención de bioetanol anhidro a partir de paja, Revista Politécnica. 2015 36(2) pp. 109. 